\title{
Mother-to-child transmission of HIV infection in Craiova Regional Center
}

\author{
Florentina Dumitrescu ${ }^{1,2}$, Eugenia-Andreea Marcu ${ }^{1,2}$, Mariana Stanescu ${ }^{1,2}$, \\ Lucian Giubelan ${ }^{1,2}$, Livia Dragonu ${ }^{1,2}$, Andreea Stoian ${ }^{1,2}$, Costin Berceanu ${ }^{1,3}$ \\ ${ }^{1}$ University of Medicine and Pharmacy,Craiova, Romania \\ 2"Victor Babes" Clinical Hospital of Infectious Diseases and Pneumoftiziology, \\ Craiova, Romania \\ ${ }^{3}$ Emergency Clinical County Hospital, Craiova, Romania
}

\begin{abstract}
HIV infection is still associated with high maternal, feto-neonatal and infant morbidity. Early detection of HIV infection during pregnancy and early initiation of antiretroviral therapy are correlated with obtaining an HIV viral load of less than $50 \mathrm{copies} / \mathrm{ml}$, in which case the risk of maternal-fetal transmission of the infection is less than $0.5 \%$.

Objectives. To establish the maternal-fetal transmission rate of HIV infection among HIV-positive pregnant women registered in Craiova Regional Center for Monitoring and Evaluation of HIVIAIDS within „Victor Babeş" Clinical Hospital of Infectious Diseases and Pneumoftiziology of Craiova (CRC) and to identify some correlations between it and certain risk factors.

Material and method. Retrospective study, during January 1st, 2014-December 31st, 2019, on 73 HIV-positive pregnant women, registered by Craiova Regional Center (CRC). For the patients included in the study group we analysed: demographic data, epidemiological data, clinical data, biological data, data provided by gynaecological and obstetrical examination, data on antiretroviral treatment (ART). The children were biologically evaluated until the age of 18 months.

Results. We found a maternal-fetal transmission rate of $6.3 \%$. For patients with complete prophylaxis measures, the maternal-fetal transmission rate was $3 \%$.

The application of complete prophylaxis measures was correlated with a low risk of vertical transmission of HIV infection $(p=0.006)$. The low adherence to ART was correlated with a high risk of maternal-fetal transmission of HIV infection $(p=0.02)$, detectable viral-HIV load (VL-HIV) $(p=0.0004)$ and advanced immunosuppression $(p=0.02)$. The disease stage of HIV-positive pregnant women was not correlated with the risk of vertical transmission of the infection $(p=1)$. The level of HIV viral load of mothers who gave birth to HIV-positive children was higher than in the general group and correlated with the maternal-fetal transmission $(p=0.04)$.

Conclusions. The maternal-fetal transmission rate in the studied period was relatively high (6.3\%), due to the incomplete application of prevention measures, 12 of the pregnant women being diagnosed during pregnancy or childbirth. The vertical transmission of HIV infection was correlated with detectable HIV viremia and low ART adherence in pregnant women.
\end{abstract}

Keywords: HIV, maternal-fetal, transmission

\section{INTRODUCTION}

At the end of 2019, the number of people infected with the human immunodeficiency virus (HIV) globally was about 37.9 million, of which 19.6 million were women. $82 \%$ of the 1.3 million pregnant women living with HIV infection worldwide have received antiretroviral treatment (ART) to prevent the vertical transmission of the infection (1). 
In Romania, according to the data of the Department for Monitoring and Evaluation of HIV / AIDS, as of December $31^{\text {st }}, 2019$, there were 16,486 people living with HIV / AIDS, of which 6460 were women. In 2019, 185 children were born to HIV-positive mothers and 184 received ARV prophylaxis, 13 children being HIV-positive (2).

HIV infection is still associated with high maternal, feto-neonatal and infant morbidity (3). The rate of perinatal transmission of human immunodeficiency virus in the absence of prevention strategies in the prenatal period or labor and birth is between $15 \%$ and $45 \%$ (1). The programs designed to prevent the mother-to-chlid transmission of HIV infection are part of the strategy to eliminate new cases of HIV infection in children (4).

In the absence of ART, more than $80 \%$ of transmission cases occur after 36 weeks of amenorrhea, during labor or birth, and only $2 \%$ of transmission occurs in the first two trimesters of pregnancy (5). The vertical transmission can be prevented by prenatal screening, pregestational ART and adapted obstetrical attitude $(3,6)$.

The main predictor factor of maternal-fetal transmission is the maternal plasma HIV viral load (VLHIV) (7). Other pregestational risk factors are the low maternal plasma levels of CD4 $\mathrm{T}$ lymphocytes and advanced maternal disease (AIDS) (8). The obstetric factors with a role in facilitating the vertical transmission of HIV infection are: vaginal delivery, premature birth, invasive obstetric procedures during pregnancy (amniocentesis, cordocentesis), chorioamniotitis, premature rupture of membranes (9).

Early detection of HIV infection during pregnancy and early initiation of antiretroviral therapy is correlated with obtaining an HIV viral load of less than 50 copies $/ \mathrm{ml}$, in which case the risk of maternal-fetal transmission of the infection is less than $0.5 \%$. The risk reduction can be achieved by: the suppression of maternal viral load by administration of antiretrovirals to the mother until at least the third trimester of pregnancy and especially during labor, the reduction of fetal exposure by scheduling a caesarean section, the post-exposure prophylaxis of newborn, the artificial feeding of the newborn (10).

The objectives of this study are to determine the rate of mother-to-child transmission of HIV infection among HIV-positive pregnant women registered in Craiova Regional Center for Monitoring and Evalua- tion of HIV / AIDS within „Victor Babeş” Clinical Hospital of Infectious Diseases and Pneumoftiziology of Craiova (CRC) and to identify some correlations between it and certain risk factors.

\section{MATERIAL AND METHODS}

We performed a retrospective study, during January $1^{\text {st }}, 2014$ and December $31^{\text {st }}, 2019$, on 73 HIVpositive pregnant women registered within CRC.

For the patients included in the study group we analysed: demographic data, epidemiological data, clinical data (complete clinical examination, presence or absence of associated HIV pains), biological data (serology for hepatitis virus co-infection, serology for Toxoplasma gondii and cytomegalovirus infections, establishment of CD4 + T lymphocyte count by flow cytometry - FACS-COUNT flow cytometer, establishment of HIV viral load by Polymerase chain reaction -PCR), data provided by gynaecological and obstetrical examination, data on antiretroviral treatment (duration of administration, type of regimen used) and data on the results of the ART adherence questionnaire, their interpretation by the psychologist and the measures taken to improve the level of ART adherence.

The level of adherence was assessed according to the criteria of the adherence questionnaire (11):

- 20-22 points $=$ adherence $\geq 95 \%$

- $18-19$ points $=80 \%<$ adherence $<95 \%$

- under 18 points $=$ non- non- adherence $(<80 \%)$

We evaluated the children at birth, at 14-21 days, at 1-2 months, at 2-3 months, at 4-6 months, at 12 months by establishing the HIV viral load (PCR-HIV RNA). After 18 months, the HIV status of the children was assessed by performing anti-HIV 1+2 ELISA and Western Blot HIV tests.

The data were collected using the electronic database and medical documents of the patients registered within CRC. For statistical data processing we used the Data Analysis module of the Microsoft Excel software, and for statistical correlations the significance threshold was $\mathrm{p}<0.05$. The obtained results were synthesized in tables and figures.

\section{RESULTS}

Among the 73 HIV-positive pregnant women we evaluated, 78 births were recorded in the study period 
- 3 of the patients had two births and one patient had 3 births. One patient had twin pregnancy obtained by in vitro fertilization. 79 children were born: 3 dead fetuses, 5 confirmed newborns with HIV infection and $71 \mathrm{HIV-positive} \mathrm{children.} \mathrm{Analysing} \mathrm{the} \mathrm{status} \mathrm{of}$ children exposed perinatal to HIV infection, we found a maternal-fetal transmission rate of $6.3 \%$. For patients with complete prophylaxis measures, the maternal-fetal transmission rate was $3 \%$.

Regarding the annual distribution of the number of HIV-positive pregnant women, we found that the highest number was registered in 2018 (17 cases $21.8 \%$ ) and the lowest in 2017 (8 cases - 10.2\%).

The basic characteristics of the group are presented in table 1.

TABLE 1. Basic characteristics of the group

\begin{tabular}{|l|l|c|}
\hline \multicolumn{2}{|l|}{ Basic characteristics of the group } & $\begin{array}{c}\text { Number of } \\
\text { patients no } \\
\text { (\%) }\end{array}$ \\
\hline $\begin{array}{l}\text { Mother's age a st } \\
\text { birth }\end{array}$ & $\begin{array}{c}2(2.7 \%) \\
10(13.7 \%)\end{array}$ \\
& $19-24$ years old & $60(82.2 \%)$ \\
& $25-33$ years old & $1(1.4 \%)$ \\
\hline \multirow{4}{*}{ HIV inf } & $\geq 34$ years old & $61(83.6 \%)$ \\
& Pribr to pregnancy & $7(9.6 \%)$ \\
\hline Probable transmission & During pregnancy & \\
routes of pregnant & or labor & $5(6.8 \%)$ \\
women & At birth & $52(71.2 \%)$ \\
\hline Environmental origins & Sexual & $21(28.8 \%)$ \\
& & $17(23.3 \%)$ \\
\hline Educa & Urban & $56(76.7 \%)$ \\
\hline
\end{tabular}

The median age of pregnant women at the time of diagnosis of HIV infection was 16 years [3:32], and at the first birth 27 years [14:34].

Regarding the HIV status of couples, there were 25 cases (34.2\%) with both HIV-positive partners, 46 cases (63\%) of serodiscordant type and 2 cases $(2.8 \%)$ with unknown HIV status (untested partner).

Of the 73 pregnant women in the study, $49(67.1 \%)$ were in the AIDS stage (clinical and immunological) at the time of the first birth (figure 1).

The immuno-virological evaluation of pregnant women showed an average immunosuppression, with a median CD4 lymphocyte of 413 cells / $\mathrm{mm}^{3}$ [19:1,272], $41 \%$ of pregnant women with CD4 $>500$ cells $/ \mathrm{mm}^{3} ; 26 \%$ of pregnant women had undetectable VL-HIV at birth.

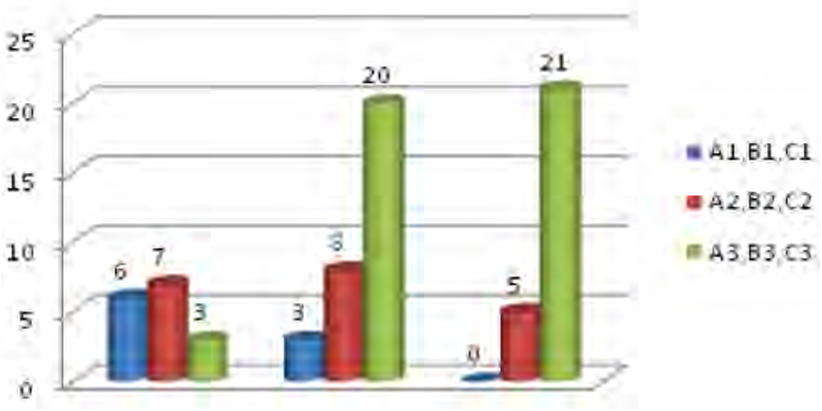

FIGURE 1. Clinical and immunological classification of HIV-positive pregnant women

The pregnant women in the studied group also presented co-infections/ infections during pregnancy, of which the most common was the chronic viral hepatitis $\mathrm{B}-10$ cases $(13.7 \%)$.

TABLE 2. Co-infections/infections in pregnant women in the studied group

\begin{tabular}{|l|c|}
\hline Chronic viral hepatitis B & 10 cases $(13.7 \%)$ \\
\hline Chronic viral hepatitis B+D & 1 case $(1.4 \%)$ \\
\hline $\begin{array}{l}\text { Anti-Toxoplasma gondii IgG antibodies - } \\
\text { present }\end{array}$ & 9 cases $(12.3 \%)$ \\
\hline $\begin{array}{l}\text { Anti-cytomegalovirus IgG antibodies } \\
\text { present }\end{array}$ & 7 cases $(9.6 \%)$ \\
\hline Syphilis & 2 cases $(2.7 \%)$ \\
\hline Pulmonary tuberculosis & 2 cases $(2.7 \%)$ \\
\hline
\end{tabular}

We found the presence of comorbidities such as hypertension in 2 of the patients (grade III of hypertension and gestational hypertension) and asthma in one patient.

The HIV-positive pregnant women received psychological counselling and regular clinical and biological evaluations were performed to accurately monitor and inform patients about measures to prevent the vertical transmission of HIV infection. The infectious disease physician who cared for the HIVpositive pregnant woman collaborated with the obstetrician, the latter scheduling a caesarean section for patients who presented according to the evaluation schedules.

66 patients $(90,4 \%)$ received ART for the prophylaxis of mother-to-child transmission of HIV infection. The most commonly used ART was Lamivudine /Zidovudine (3TC/ZDV) + Lopinavir/Ritonavir (LPV/r) -31 cases (47\%). 64 patients received prophylactic treatment throughout the pregnancy, and 2 patients received treatment only in the last trimester of pregnancy. One patient refused ART during pregnancy 


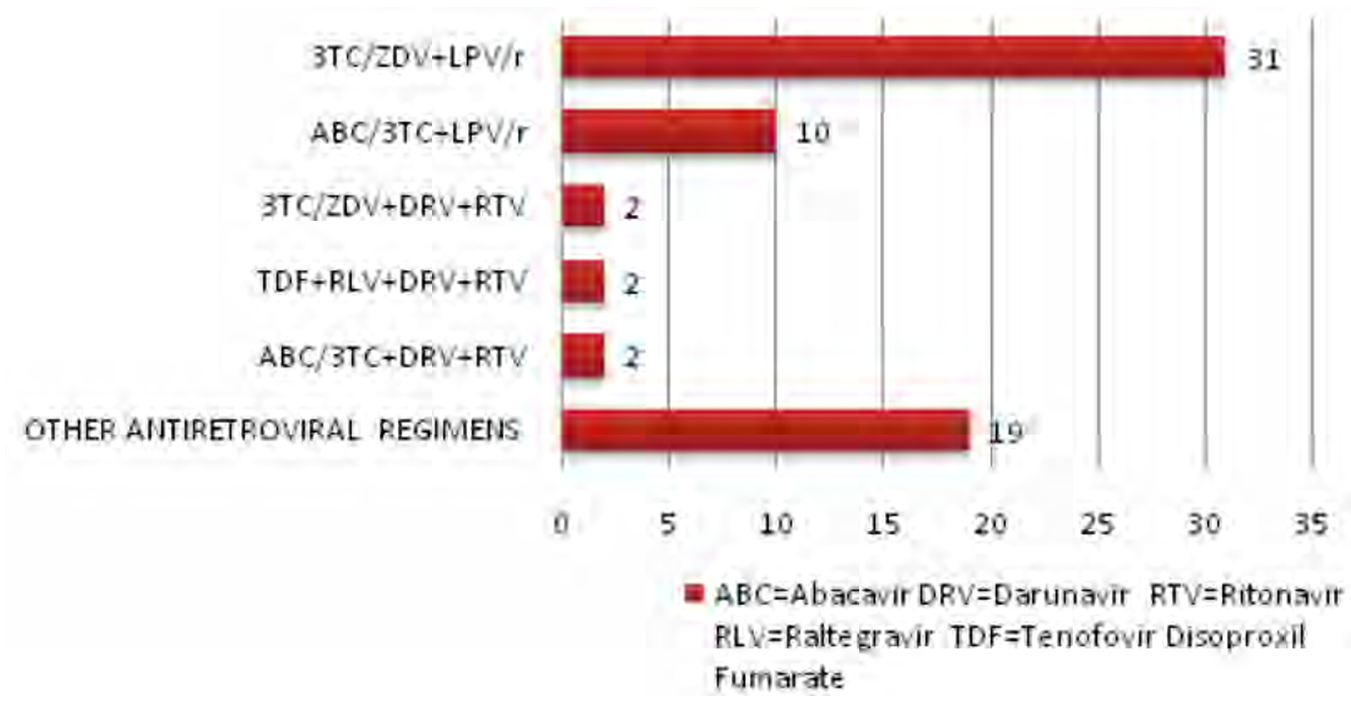

FIGURE 2. Antiretroviral therapies used in HIV-positive pregnant women

The median duration of treatment until the first birth was 11 years [0:24].

The pregnancy adherence to ART was assessed by applying the adherence questionnaire, which is completed periodically for all HIV-infected patients registered within CRC. We found that 18 patients $(27.3 \%)$ were non-adherent to ART (adherence $<80 \%$ ).

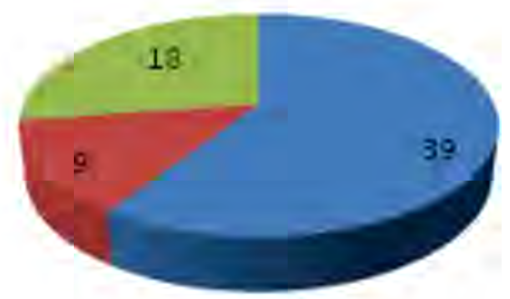

\section{Adherence $\geq 95 \% \quad$ : $80 \%<$ Adherence $<95 \%$ \\ Adherence $<80 \%$}

FIGURE 3. Adherence to ART of HIV-positive pregnant women

Compared to the type of birth, 11 women (14.1\%) gave birth naturally and 67 women $(85.9 \%)$ by caesarean section. In the case of the 6 patients diagnosed with HIV infection before pregnancy, who gave birth vaginally, this was the result of either presenting patients in labor or was the patients' choice (they refused the scheduled caesarean section).

The application of complete prophylaxis measures (administration of ART to the mother, the caesarean delivery, ART prophylaxis and artificial feeding of the newborn) was correlated with a low risk of vertical transmission of HIV infection $(\mathrm{p}=0.006)$.
The low adherence to ART was correlated with a high risk of maternal-fetal transmission of HIV infection $(\mathrm{p}=0.02)$, detectable VL-HIV $(\mathrm{p}=0.0004)$ and advanced immunosuppression $(\mathrm{p}=0.02)$.

Of the 5 children infected vertically with HIV, 2 were born naturally and 3 children by caesarean section. There were no statistically significant differences between vaginal delivery and caesarean delivery regarding the rate of mother-to-child transmission of HIV infection $(\mathrm{p}=0.1)$.

All newborns received ARV prophylaxis for 6 weeks; the most used combination being ZDV + 3TC72 children (96\%) and they were all artificially fed.

3 of the HIV-positive children came from mothers parenterally infected with HIV between 1987 and 1990, and the other 2 came from sexually infected mothers with HIV.

The clinical-immunological staging at birth of the 5 HIV-positive pregnant women, who transmitted the infection vertically, was as follows: a pregnant woman in stage $\mathrm{C} 3$, a pregnant woman in stage $\mathrm{C} 2$, a pregnant woman in stage B3, a pregnant woman in stage B2 and a pregnant woman in stage A2 (diagnosed in the seventh month of pregnancy, with ART initiated immediately after detection). The disease stage of HIV-positive pregnant women was not correlated with the risk of vertical transmission of the infection $(\mathrm{p}=1)$.

The immunological evaluation of mothers who transmitted HIV infection vertically, showed a moderate degree of immunosuppression with a median CD4 lymphocytes of 319 cells $/ \mathrm{mm}^{3}$ [74:478]; there were 
no statistically significant differences compared to the group with negative children. The HIV viral load level of mothers who gave birth to positive children was higher than in the general group, two patients with viremia greater than 10,000 copies/ml; the HIV viral load level was correlated with the maternal-fetal transmission $(\mathrm{p}=0.04)$.

\section{DISCUSSIONS}

The pregnancy in the context of HIV remains a risk situation in all cases, so the management of HIVpositive pregnant women must be ensured by a multidisciplinary team for a complete and correct approach.

Specific recommendations and care were developed for HIV-positive pregnant women and newborn, and the rigorous implementation of these measures has led to a significant reduction in the vertical transmission of HIV infection at a rate of less than $1 \%$ $(12,13)$.

In a large cohort study conducted in Ukraine between 2000 and 1012, a group of 8,884 patients diagnosed with HIV infection previously during pregnancy and intrapartum, who gave birth to live fetuses, was analysed. The diagnosis of HIV infection was established prior to pregnancy in $35 \%$ of cases $(2,951$ patients), compared with $65 \%$ who were diagnosed during pregnancy as follows: $19 \%$ (1,623 patients) diagnosed in the first trimester, $27 \%$ (2,291 patients) in the second trimester, $15 \%$ (1,217 patients) in the third trimester, respectively $4 \%$ of cases (310 patients) diagnosed at birth. $83 \%$ of mothers received ART during pregnancy. In $30 \%$ of cases, the birth took place by scheduled caesarean section, in $4 \%$ of cases by emergency caesarean section, and in $66 \%$ of cases by natural means. This study showed that the negative results are conditioned by both the risk factors directly associated with HIV infection and the risk factors common to the general population, highlighting the importance of monitoring pregnancies and antiretroviral treatment among HIV-positive pregnant women (14).

In the study we performed, we identified a rate of $6.3 \%$ of maternal-fetal transmission of HIV infection, compared to a higher rate $(9.3 \%)$ reported to CRC in the period 2007-2011 (15). The vertical transmission of HIV infection has been associated with increased
HIV viremia and low adherence to ART similar to data from several studies (16-18).

Another cohort study was performed in Ethiopia between January 2014 and December 2017 on 313 HIV-positive pregnant women. The maternal-fetal transmission rate of HIV infection was 3.8\%. The absence of regular examinations during pregnancy (56 patients $-19.9 \%$ ), home birth (51 patients $-16.3 \%$ ), absence of ART in pregnant women (23 patients $7.3 \%$ ) and prophylactic ART in newborns (21 newborns did not receive ART $-6.7 \%$ ) were significant risk factors associated with vertical transmission of HIV infection (19).

The correct administration of ART to HIV-positive pregnant women, in order to obtain and maintain viral suppression, remains the main objective of care, this being one of the most important factors influencing the vertical transmission of HIV infection.

Diagnosing HIV infection in pregnant women at birth brings to light deficiencies in the care and monitoring of pregnant women; it is necessary to inform all women who want to have a child about the need for HIV testing, in order to be able to make an informed decision, depending on their HIV status.

\section{CONCLUSIONS}

The rate of mother-to-child transmission of HIV infection in the studied period was relatively high $(6.3 \%)$, due to the incomplete application of prevention measures.

There were deficiencies in the care and monitoring of pregnant women, 12 of the pregnant women being diagnosed during pregnancy or at the birth of the child.

The vertical transmission of HIV infection was correlated with detectable VL-HIV and low adherence to ART in pregnant women.

The correct establishment of complete prophylactic measures (ART in the mother, adherence to treatment, caesarean section, ART prophylaxis and artificial feeding of the newborn) was accompanied by a low risk of maternal-fetal transmission of HIV, requiring the intervention of a multidisciplinary team for monitoring the HIV-positive pregnant woman and the child perinatally exposed to HIV infection.

Conflict of interest: none declared Financial support: none declared 


\section{REFERENCES}

1. https://www.who.int/news-room/fact-sheets/detail/hiv-aids. [Online] November 15, 2019 [Cited April 30, 2020].

2. http://cnlas.ro/com_jce/date-statistice.html [Online] [Cited May 05, 2020].

3. Royal College of Obstetricians and Gynaecologists. HIV in Pregnancy, Management (Green-top Guideline No. 39). Published 2010.

4. Gubert De Matos VT, Lyrio De Oliveira AL, Ribeiro Dos Santos E et al. Missed opportunities for prevention of perinatal HIV infection. Braz J Infect Dis. 2015;19(5):554-555.

5. Kourtis AP, Bulterys M, Nesheim SR, Lee FK. Understanding the timing of HIV transmission from mother to infant. The Journal of the American Medical Association. 2001;(285):709-12.

6. http://www.guideline.gov/summary/summary.aspx?doc_id=7676\&nbr $=004475 \&$ string=Management+AND+ HIV+AND+pregnancy. [Online] 2004. [Cited April 24, 2020.]

7. Garcia PM, Kalish LA, Minkoff H, Quinn TC, Burchett SK et al. Maternal levels of plasma human immunodeficiency virus type 1 RNA and the risk of perinatal transmission. N Engl J Med. 1999; 341:394-402.

8. European Collaborative Study. Maternal viral load and vertical transmission of HIV-1: An important factor but not the only one. AIDS. 1999;13:1377-85.

9. European Collaborative Study. Risk factors for mother-to-child transmission of HIV-1. Lancet. 1992;339(8800):1007-1012.

10. European AIDS Clinical Society (EACS) Guidelines for treatment of HIV-positive adults in Europe. October 2018 - available at https:// www.eacsociety.org/files/2018_guidelines-9.1-english.pdf.

11. Drăgănescu $M$, lancu $A V$, Modrigan $M$, Arbune $M$. Aderența la tratamentul antiretroviral și trăsăturile de personalitate ale pacienților cu infecție HIV. Probleme de patologie infecțioasă la frontiere. Conferința Națională cu participare internaţională „Patologia infecțioasă la frontiere" Galați, 7-9 iunie 2018, Editura GUP, 2018.

12. https://www.cdc.gov/hiv/group/gender/pregnantwomen/index.html [Online] 2019. [Cited May 12, 2020].

13. Townsend CL, Cortina-Borja M, Peckham CS et al. Low rates of mother-to-child transmission of HIV following effective pregnancy interventions in the United Kingdom and Ireland, 2000-2006. AIDS. 2008;22(8):973-81.

14. Bakeris E, Malyuta R, Volokha A et al. Pregnancy Outcomes in HIV-positive Women in Ukraine, 2000-12 (European Collaborative Study in EuroCoord): An Observational Cohort Study. Lancet HIV. 2015;2(9:e385-92.

15. Dumitrescu F, Cupșa A, Giubelan L et al. Expunerea perinatală la infecția cu HIV în perioada 2007-2011 în județul Dolj. Ro J Infect Dis. 2012;15(3):194-195.

16. Warszawski J, Tubiana R, Le Chenadec J et al. Mother-to-childtransmission despite antiretroviral therapy in the ANRS French Perinatal Cohort. AIDS. 2008;22:289-99.

17. Teasdale CA, Marais BJ, Abrams EJ. HIV: Prevention of mother-tochild transmission. BMJ Clin Evid. 2011.

18. Hurst SA, Appelgren KE, Kourtis AP. Prevention of mother-to-child transmission of HIV Type 1: the role of neonatal and infant prophylaxis. Expert Rev Anti Infect Ther. 2015:169-181.

19. Yitayew YA, Bekele DM, Demissie BW, Menji ZA. Mother to Child Transmission of HIV and Associated Factors Among HIV Exposed Infants at Public Health Facilities, Dessie Town, Ethiopia. HIVIAIDS - Research and Palliative Care. 2019;11. 